\title{
Ontario's plan for electronic health records is at risk, official
}

\section{says}

Published at www.cmaj.ca on Mar. 2

$\mathrm{O}$ ntario must move faster with a series of legislative and regulatory measures in order to meet its commitment to create electronic health records for all residents by 2015 , a senior official with eHealth Ontario says.

"It's time the province decided if it's really committed to this or not," argues Doug Tessier, senior vice-president of development and implementation for the agency responsible for implementing the government's multibillion-dollar electronic health records (EHR) strategy.

Progress on the province's EHR file was hampered by the eHealth Ontario scandal surrounding compensation for consultants, Tessier says. The scandal triggered an audit, which concluded that the provincial government wasted over $\$ 1$ billion, and ultimately led to the resignations of former health minister David Caplan and former deputy minister of health Ron Sapsford.

"The swirl and scandal has hurt us," says Tessier, considered the government's expert on electronic health systems.

But Ontario's EHR woes predate the scandal, Tessier says, arguing that there have consistently been delays in making key political decisions since the province first committed to implementation in 2000.

Deliberations on major decisions within the Ministry of Health and Long-Term Care have often taken two years, Tessier says. "If you are really committed to this, two years is too long. ... To my mind, if the government is not committed to something, they hem and haw.'

Moreover, even the basic, legal framework for patient EHRs - which will require changes to laws governing patient record management and privacy - still isn't in place, more than seven years after

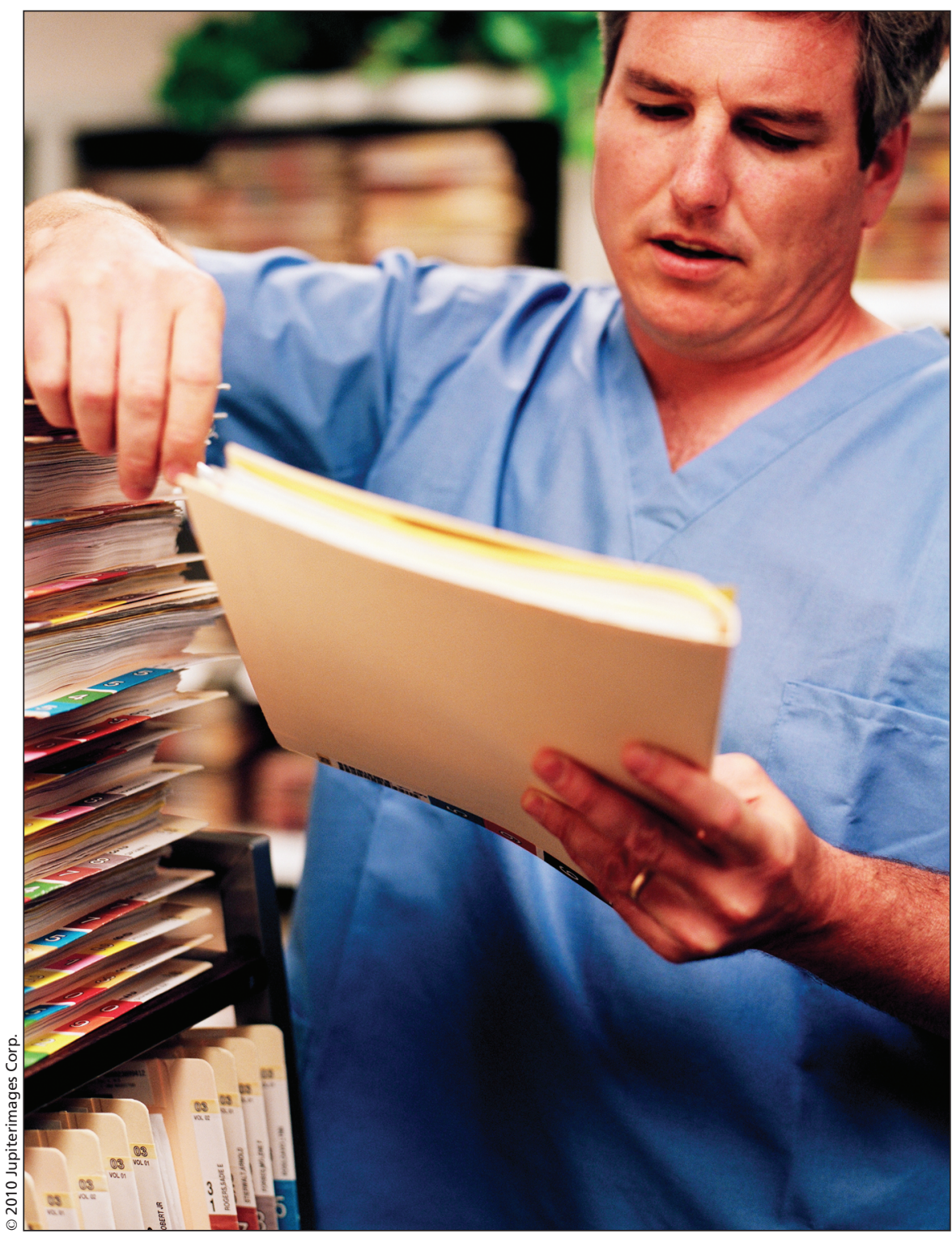

Doctors in Ontario may still be using paper records in 2015, despite the province's commitment to create electronic health records for all residents by then.

the province established the agency, Tessier says. Not only are "two or three pieces of new legislation" still required, "but we've also got to undo a number of pieces of [existing] legislation."

The government must also do more to persuade health regulatory colleges to overhaul policies that impact on
EHRs, Tessier argues. "Let's put our arm around them and gently bring them into the 21 st century. ... With the regulations, the legislation and the policy changes that government has to do, that's not so gentle. That's on the critical path. If they don't do it, we're blocked completely." 
Tessier also argues that Ontario's program to encourage physicians and other health care providers to utilize EHRs must be expanded. Under the program, the government absorbs $70 \%$ of costs associated with a physician's move to EHRs but financial constraints have limited its reach. "It only goes to 9600 [of 24 600] physicians."

Physicians should be required to use EHRs, including applications such as eprescribing, and to that end, the government should make the use of EHRs a condition of payment for medical services rendered, Tessier says.

Tessier also notes that Auditor General Jim McCarter correctly identified that implementing EHRs in Ontario has been complicated by a decision to build the broad information technology infrastructure before developing applications. As McCarter stated in his report, that situation might have been avoided "had there been an overall strategic plan driving the EHR initiative from the very beginning."

Tessier says there's also a need for more standardization of platforms and systems. Ontario's hospitals have developed at least nine different internal electronic records systems, some of which have cost as much as $\$ 100$ million, he notes. Scores of subsystems have also been developed in labs, pharmacies and clinics. Ontario physicians use at least 20 different electronic records systems.

Integrating those systems is problematic as many are incompatible, because of commercial competition between system vendors.

Moreover, such systems must somehow reach Ontario's 13 million patients, said Bill Albino, former head of Smart Systems for Health Agency, the nonprofit provincial government agency responsible for establishing a provincewide technology infrastructure.

In a speech at the Waterloo Institute for Health Informatics in March 2008, Albino estimated that a properly functioning EHR system would yield annual cost savings of at least $6 \%$ across the province's $\$ 42.5$-billion sys- tem, or about \$2.4-billion. He argued the savings would be even higher as EHRs improve patient outcomes.

Brian Hutchison, a primary health care analyst at McMaster University in Hamilton, Ontario, says there are consequences to the province's failure to adequately invest in EHRs. Had the government recognized that EHRs quickly pay for themselves, and invested earlier, the health care system would be delivering improved care, he says. "It was a tactical error. We're now paying the price." - Paul Christopher Webster, Toronto, Ont.

DOI:10.1503/cmaj.109-3193

Second of a series on electronic health records

Part 1: Canada's electronic health records initiative stalled by federal funding freeze (CMAJ 2010. DOI:10.1503/cmaj.109-3183) 